\title{
Advances in the Aetiophatogenesis of Sjögren's Syndrome: a Literature Review
}

\author{
Pedro de Sousa Gomes ${ }^{1}$, Gintaras Juodzbalys ${ }^{2}$, Maria Helena Fernandes ${ }^{1}$, Zygimantas Guobis ${ }^{3}$ \\ ${ }^{1}$ Laboratory of Pharmacology and Cellular Biocompatibility, Faculty of Dental Medicine, University of Porto, Porto, Portugal. \\ ${ }^{2}$ Department of Maxillofacial Surgery, Medical Academy, Lithuanian University of Health Sciences, Kaunas, Lithuania. \\ ${ }^{3}$ Department of Dental and Oral Pathology, Medical Academy, Lithuanian University of Health Sciences, Kaunas, Lithuania.
}

\author{
Corresponding Author: \\ Pedro de Sousa Gomes \\ Laboratory of Pharmacology and Cellular Biocompatibility \\ Faculty of Dental Medicine, University of Porto \\ Rua Dr. Manuel Pereira da Silva \\ 4200-393 Porto \\ Portugal \\ Tel. +351220901100 \\ Fax. +351220901101 \\ E-mail:pgomes@,fmd.up.pt
}

\begin{abstract}
Objectives: The purpose of present paper is to review and critically address the recent advances on the aetiopathogenesis of the Sjögren's syndrome, taking into account the attained clinical features, with particular relevance given to the oral involvement. Material and Methods: A comprehensive review of the available literature between 1970 and 2012, regarding to the aetiopathogenesis and clinical findings related to Sjögren's syndrome was conducted. Eligible studies were identified by searching the electronic literature PubMed, Medline, Embase, and ScienceDirect databases for relevant reports (last search update January 2012), combining the MESH heading term "Sjögren's syndrome", with the words "salivary glands, xerostomia, xerophtalmia, aetiology". The authors checked the references of the selected articles to identify additional eligible publications and contacted the authors, if necessary.

Results: This article addresses a large number of the recent advances in the aetiopathogenesis of the disease, taking into account the attained clinical features of both local and systemic nature. Detailed mechanisms of the hypothesized influence of viral infections, genetic and hormonal factors, and the relevance of the altered glandular homeostasis are critically discussed with particular relevance given to the local and systemic involvement of Sjögren's syndrome.

Conclusions: The increasing number of data published recently on the aetiophatogenesis of Sjögren's syndrome strengthens the hypothesis that this condition, as all autoimmune diseases, is a multifactor disorder. Genetic predisposition, hormonal and environmental factors are thought to be implicated.
\end{abstract}

Keywords: oral pathology; Sjogren's syndrome; salivary glands; xerostomia; xerophthalmia; aethiology.

Accepted for publication: 17 March 2012

To cite this article:

Gomes PD, Juodzbalys G, Fernandes MH, Guobis Z. Advances in the Aetiophatogenesis of Sjögren's Syndrome: a Literature Review.

J Oral Maxillofac Res 2012 (Jan-Mar);3(1):e2

URL: http://www.ejomr.org/JOMR/archives/2012/1/e2/v3n1e2ht.pdf

doi: $10.5037 /$ jomr.2012.3102 


\section{INTRODUCTION}

Sjögren's syndrome (SS) is a chronic systemic disease that primarily involves salivary and lachrymal glands, being considered an autoimmune exocrinopathy. The syndrome is clinically characterized by keratoconjunctivitis sicca and xerostomia, caused by inflammation - histologically identified as a focal lymphocytic infiltration of the affected glands [1]. The syndrome may appear alone, being designated as primary SS (pSS), or associated with other autoimmune disease (e.g. rheumatoid arthritis, systemic lupus erythematous, and systemic sclerosis), traditionally reported as secondary SS (sSS) [2].

Sjögren's syndrome is one of the most prevalent autoimmune diseases, with an estimated 0.4 to 3.1 million affected individuals in the USA alone, and with a female over male preponderance of $9: 1[\underline{3}, \underline{4}]$. Although the sicca symptoms are the hallmarks of the syndrome, during the disease course, any organ or mucosal surface may be involved and patients might experience a huge number of clinical manifestations, including constitutional symptoms, arthralgias or arthritis, skin vasculitis, haematological disorders, interstitial disease of the lung, kidney failure, peripheral or central neuropathies and gastro-intestinal tract disorders. Thus, SS can be considered as a heterogeneous autoimmune entity that may manifest within a wide spectrum of disease, ranging from a limited organ-specific autoimmune exocrinopathy features, to a systemic condition with extensive autoimmune clinical, serological abnormalities and scattered complications [1,5-7]. These complexities have made difficult to identify homogenous group of patients with a shared aetiopathogenesis or prognosis. This is further complicated by the difficulty of reaching a diagnosis in the early stages of the disease, the lack of a specific diagnostic test for SS, and the fact that oral and ocular dryness are broadly common symptoms in the general population. Therefore, this paper aims to review and critically address the recent advances on the aetiopathogenesis of the Sjögren's syndrome, taking into account the attained clinical features, with particular relevance given to the oral involvement.

\section{MATERIAL AND METHODS}

A comprehensive review of the available literature between 1970 and 2012, regarding to the aetiopathogenesis and clinical findings related to SS was conducted. Eligible studies were identified by searching the electronic literature PubMed, Medline, Embase and ScienceDirect databases for relevant reports (last search update January 2012), combining the MESH heading term "Sjögren's syndrome", with the words "salivary glands, xerostomia, xerophtalmia, aetiology". The authors checked the references of the selected articles to identify additional eligible publications and contacted the authors, if necessary. This article addresses a large number of the recent advances in the aetiopathogenesis of the disease, taking into account the attained clinical features of both local and systemic nature. Detailed mechanisms of the hypothesized influence of viral infections, genetic and hormonal factors, and the relevance of the altered glandular homeostasis are critically discussed with particular relevance given to the local and systemic involvement of SS. However, it is not possible to comprehensively discuss every subject, because that would require a text too extensive for a single article. When appropriate, references are cited.

\section{Aetiopathogenesis}

The aetiopathogenesis of SS is still obscure and involves several different but interrelated processes. The heterogeneity verified on SS advocates that the individual clinical manifestations result from stochastic interactions between the environment and a geneticallymediated susceptible host. Given the convincing evidence of epithelium activation in the affected organs and tissues, as verified by the inappropriate major histocompatibility complex (MHC) expression, overexpression of co-stimulatory molecules and altered cytokine function, extensive research has focused on the identification of the detailed mechanisms related to SS establishment and development. Several hypotheses have been proposed to substantiate the complexity of SS clinical manifestations.

\section{Genetic factors}

A genetic predisposition for SS was first demonstrated when the disease susceptibility was associated with MHC Class II alleles, mainly HLA-DR and HLA-DQ []. Affected individuals of different ethnic origins carry different HLA susceptibilities, e.g. affected Caucasians from the north and western Europe showed a high prevalence of the haplotypes D8, DRw52 and DR3 [9], while Scandinavians report an association with DR2 [10] and Greeks with DR5 [11]. Distinct HLA class II haplotypes have also been correlated with the presence of specific autoantibodies. In fact, the presence of autoantibodies Ro/SSA and La/SSB - a hallmark of the disease - was correlated with HLA-DR3, HLADQA and HLA-DQB alleles [12]. A meta-analysis of 
worldwide conducted case control trials of SS aimed to identify common HLA Class II alleles contributing to the aetiology of pSS. At worldwide level, the most significant risk and protective alleles found were DRB1*03:01, DQA1*05:01, DQB1*02:01, DRB1*03 and DQA1*03:01, DQA1*05:01, DQB1*05:01, respectively. Furthermore, the authors reported that common susceptibility variants where found to be part of a common genetic background shared between pSS and other autoimmune diseases [13].

In a distinct approach, polymorphisms of IFR-5 and STAT4 genes (involved in the activation of the type I interferon [IFN] pathway), in the leukocyte receptor FCGR3B and pro-inflammatory cytokine CCL3L1, were also found to confer susceptibility to SS development $[14,15]$.

\section{Hormonal factors}

Sex hormones influence the establishment and development of humoral and cell-mediated immune responses. Estrogen is currently considered to be mainly responsible for gender immunological dimorphism and thus, decreased ovarian production of estrogens could be involved in the establishment and development of autoimmune-related syndromes. In SS, the perimenopausic female predominance, age onset, and/or disease course, in conjunction with available data from animal models, substantiate the putative role of estrogen deficiency in the etiophathogenesis of the disease [16]. Immunological mechanisms are related with the increased presentation of autoantigens to effector T cells, in estrogen deficitary conditions [17]. Androgen deficiency, both locally and systemically, has also been pointed out to be a key factor prompting SS. Reduced plasmatic levels (up to $40-50 \%$ ) of dehydroepiandrosterone sulfate (DHEA-S), the precursor sex steroid hormone produced in the adrenal cortex, has been identified in SS-affected individuals, comparing to age and sex matched controls $[18,19]$. Furthermore, there is evidence of hypo-functioning of the hypothalamic-pituitary-adrenal axis in SS-affected women, as shown by a selective failure to produce DHEA-S after stimulation of the hypothalamicpituitary-adrenal axis with corticotropin-releasing hormone (CRH) [19,20].

\section{Viral infections}

A compelling body of evidence has been gathered to justify the central role of the activation of type I interferons (IFNs) in the establishment of SS and several other autoimmune conditions [21]. Type I IFNs are produced by many cell types including lymphocytes, macrophages, fibroblasts, endothelial cells and dendritic cells, among others, in response to viral infections. SS is characterized by individual clinical manifestations with distinct organ involvement, although the activation of type I IFNs is a shared and central event in SS aetiology. Increased type I IFNs plasmatic levels were found in patients with pSS. Furthermore type I IFNs mRNA levels were found to be increased in peripheral blood cells and lymphocytes, while epithelial cells positive for type I IFNs where detected in labial salivary glands of pSS-affected individuals [22]. Under these circumstances, the fundamental question that arises is the reason for the augmented production of classic anti-viral effector molecules, within the range of this autoimmune condition. Tentative candidates have been proposed as potential initiating factors, and virus from the genus Parvovirus, Cytomegalovirus, Deltaretrovirus and Lymphocryptovirus have been proposed [23-25]. Nonetheless the attained observations, more recent and converged evidences only allowed the establishment of broadly weak association between viral infections and the initiation of the histopathological lesion in SS $[\underline{26}, \underline{27}]$. Despite the unclear association, a high incidence of Epstein Barr virus and hepatitis $\mathrm{C}$ virus $(\mathrm{HCV})$ infections have been reported, particularly in some restricted SS-affected populations [28]. Accordingly, the prevalence of antibodies to HCV, in patients with pSS, has been reported to range from 15 to $20 \%$, as assessed by enzyme linked immunosorbent assay, and the detection of HCV viraemia in pSS-affected patients, using polymerase chain reaction, has been reported to range from 0 to $20 \%$ - values significantly higher than those attained of $\mathrm{HCV}$ infection in the general population (around 1\%) [29, 30].

Apart from the identification of the initiating trigger, the activation of the type I IFNs pathway might be a linkage between the innate mechanisms of the immunological response and the generation of the adaptive response, embracing only a slight glance of the immunoregulation process of this condition.

\section{Altered glandular homeostasis}

Salivary glands of SS-affected individuals are characterized by abnormalities of glandular epithelial cells that occur before infiltration by auto reactive lymphocytes. Such idiosyncrasies include disturbed cell proliferation/apoptosis regulation and increased breakdown of secreted proteins [31].

Apoptosis, either in a direct or indirect way, is involved in the development of secretory dysfunction affecting the exocrine lachrymal and salivary glands [31].Two factors associated with acinar tissue apoptosis include the proteolysis of $\alpha$-fodrin and the Fas/Fas-ligand 
interaction [32]. Proteolysis of $\alpha$-fodrin is pathogenic to cells, due to the physiological involvement of the intact protein in the maintenance of the normal membrane structure and in the support of cell surface protein function [33]. $\alpha$-fodrin is a major target for caspases activity during apoptosis and its proteolysis leads to membrane malfunction and cellular shrinkage. Moreover, it has been sustained that the activation of the apoptotic pathway via $\alpha$-fodrin fragmentation could determine the exposure of cryptic epitopes, which thus would result in the production of specific autoantibodies against Ro (SSA) and La (SSB) [32]. On the other hand, the interaction Fas/Fas-L could also contribute to the activation of apoptotic pathways in SS, by inducing the downstream activation of proteinases and caspases, which lead to the fragmentation of DNA. It has been shown that SS-affected individuals are able to express the Fas antigen in their ductal epithelial cells, providing that this cellular population is a good target for effector $\mathrm{T}$ cells-mediated induction of apoptosis [31]. Effector $\mathrm{T}$ cells are able to induce apoptosis through the release of proteases such as perforin and granzyme B [34]. Furthermore, apart from the above described mechanisms, the increased rate of apoptosis in acinar tissue cells may also result from the inequity between the down-regulated apoptosis inhibitor Bcl-2 and the up-regulated apoptosis inducer Bax [ㅍ]]

Acinar and ductal cells from salivary and lachrymal glands of SS-affected individuals possess a molecular repertoire that confers an enhanced capacity to disorganize the extracellular matrix, in a process mediated by matrix metalloproteinases (MMPs). MMPs are a family of endopeptidases that play a fundamental role in tissue remodelling, both in physiological and pathological conditions. Their activity is regulated by growth factors, cytokines and hormones, as well as by direct interaction with constituents of the extracellular matrix [36]. MMPs' biological activities is counterbalanced by endogenous tissue inhibitors of metalloproteinases (TIMPs). TIMPs are constitutively expressed in many tissues including exocrine glands and fluids [36]. In SS, the expression of MMPs, in particular MMP-2, MMP-3 and MMP-9, was found to be significantly elevated in labial salivary glands and saliva [37]. Moreover, the expression of TIMPs in individuals affected by SS are altered, specifically the MMPs/ TIMPs ratio, which would contribute to an increased availability of active MMPs $[38,39]$. Increased MMPs activity lead to alterations in basal and apical acinar and ductal cells, impairing the communication between these cells and their microenvironment, deregulating the normal vesicle traffic, thus contributing to the impairment of saliva secretion [40].

\section{Local clinical features Oral manifestations}

Involvement of major and minor salivary glands leads to a decreased salivary secretion, which has a major impact in oral health of SS-affected individuals, affecting the lubricating, buffering and antimicrobial properties of saliva. Furthermore, patients may complain not of oral dryness, but of also of unpleasant taste, difficult eating dry food or difficulties in controlling the stability of removal prosthetic appliances. As a result of the xerostomic condition, an increased incidence of dental caries, mucosal friability and fungal infections (primarily candidiasis) is verified. Interestingly, the development of bacteria-related infections (such as those related to periodontal disease) is not enhanced by SS [41]. Broadly, no significant differences have been found, either in clinical or microflora parameters, of pSS- or sSS-affected patients in comparison to systemically healthy age- and gender-matched controls [42]. However, a clinical study showed that patients with SS and severe salivary hypofunction report an increased number of Streptococus mutans, Lactobacillus and Candida organisms in the supragingival plaque, while on the smooth mucosa and tongue, an increased frequency of Staphylococcus aureus, enterococci and Candida spp. were verified [43].

The enlargement of parotid and/or other major salivary glands, usually asymptomatic and self-limited, is also commonly verified. Episodes of acute bacterial sialadenitis may be frequent, with associated pain, trismus and tender swelling of the salivary gland. Accordingly, persistent enlargement should be carefully assessed in order to exclude bacterial super-infection or lymphoma development. Other oral symptoms may include soreness, dysphagia, alterations in the surface of the tongue (i.e., may become red and lobulated, with partial or complete depapillation, and fissures may appear), and in taste buds [44].

\section{Ocular manifestations}

Dry eye is the main ocular manifestation of SS, resulting from the affection of corneal and conjunctival epithelium, secondary to decrease of lachrymal secretion and altered lachrymal composition - a condition known as keratoconjunctivitis sicca. Interestingly, the lachrymal flow rate does not correlate with the severity of ocular manifestations [45].

Reported symptoms often include sensation of foreign-body, itching, soreness, grittiness, irritation, photosensitivity and thick rope-like secretions (due to impaired lachrymal film and abnormal mucus proportion), at the inner canthus [46]. Furthermore, 
ocular complications may include corneal ulceration and scarring as well as occasionally perforation, bacterial keratitis, and eyelid infections. Ocular symptoms may be aggravated by reduced levels of environmental humidity. Enlargement of the lachrymal glands has been rarely reported [46].

\section{Systemic clinical features Musculoskeletal involvement}

Joint disease associated with SS is commonly a polyarticular arthropathy which intermittently affects small joints. Evidence of joint deformity and erosion may be encountered in pSS-affected individuals, as well as nonerosive arthritis. Arthralgias, myalgias and fibromyalgia-like features are also commonly found [47].

\section{Dermatological involvement}

Dry skin is a major manifestation of SS, affecting more than half of SS-affected patients. Other forms of skin involvement, as skin rashes and altered skin sensitivity have also been reported, although less frequently [48]. Skin biopsies of patients affect by SS reveal lymphocytic infiltrates and it has been proposed the inclusion of skin biopsy as a routine analytical tool for the diagnosis of SS, especially in those patients with inconclusive histopathological analysis of minor salivary glands [49]. Raynaud's phenomenon is a highly prevalent in patients affected by pSS and usually precedes sicca manifestations. Diagnosis of Raynaud's phenomenon with SS has been described as intermittent attacks of digital pallor and/or cyanosis in the absence of any other related condition. The main identified triggers were cold and stress [50]. Also it has been correlated with an increased prevalence of extra-glandular manifestations and positive immunological markers [51].

In SS, vasculitis can vary from a cutaneous localized form to as systemic necrotizing vasculitis. In cutaneous forms, small vessel vasculitis predominates over medium vessel vasculitis. Further, it may either be lymphocytic or neutrophilic or even manifest in a hybrid pattern. Cutaneous vasculitis may be associated with mononeuritis multiplex or neuroaxial involvement, thus such patients often have anti-Ro antibodies, a positive rheumatoid factor, and mixed cryoglobulinemia included in the context of Waldenstrom's macroglobulinemia [52]. Necrotizing vasculitis of medium-sized vessels, resembling polyarteritis nodosa, can occur but is a rare occurrence in SS patients [므] .

\section{Gastrointestinal involvement}

Patients with SS are commonly affected by a varying degree of nonspecific esophageal motility disorders, and frequently gastroesophageal reflux. This converges to establish an increased risk of acidic reflux in the SS-affected patient, especially because the buffering capacity of the esophagus is further reduced by the hyposalivation [54]. Additionally, dyspepsia, moderately recurrent, may be associated with gastritis, reduced acid production, and antiparietal cell autoantibodies, but rarely pernicious anaemia [55]. Pancreatic involvement, although rare, includes pancreatitis and pancreatic insufficiency [ㄷ5].

Oesophageal dysmotility can also contribute to the development of laryngopharyngeal reflux - caused by the reflux of gastric contents into the upper aerodigestive tract, inducing local laryngeal and neighbouring modifications. Acid and enzymatic activity in the perioral tissues has been related to the development of dysphonia, chronic cough and reactive airway disease, throat pain and excessive throat mucus, dental caries and even neoplastic pathology of the larynx [56]. Furthermore, laryngopharyngeal reflux generally occurs in the absence of heartburn and oesophagitis, and regurgitation-related complications are mild, making the diagnosis challenging [드].

\section{Renal involvement}

Kidney involvement is a frequent extraglandular manifestation of primary Sjögren's's syndrome. The renal involvement is rarely overt, and more often follows a subclinical course. In some cases, it may precede the onset of subjective sicca syndrome [57]. Renal disease may manifest as tubular disease - resulting from the interstitial lymphocytic infiltration, with interstitial fibrosis and tubular atrophy - or as glomerular disease resulting from immune complex deposition and cryoglobulinemia [58]. Tubulointerstitial nephritis is the most common presentation of the renal involvement, generally characterized by a distal tubular acidosis, nonetheless nephrocalcinosis, nephrogenic diabetes insipidus or, albeit rarely, proximal renal tubular acidosis or Fanconi syndrome have been identified [59]. Untreated disease may lead to an increased tendency to stone formation, and some patients may develop renal failure [60]. In contrast to interstitial disease, the presence of glomerulonephritis is considered a severe extraepithelial manifestation, albeit a far rare one. It usually appears as a late development of course of pSS and is correlated with an increased morbidity and mortality rates. The most commonly identified glomerulonephritis forms in pSS are membranoproliferative, mesangioproliferative, and less frequently, membranous [61]. They are often associated with mixed cryoglobulinemia and hypocomplementemia [ [58]. 


\section{Hepatic involvement}

Liver involvement in pSS is generally rare, subclinical, and does not lead to cirrhosis. Elevated liver enzymes and antimitochondrial antibodies are the most sensitive indicators of underlying liver disease [62]. The overlap between primary biliary cirrhosis and pSS has, for long, been established [63]. In fact, both conditions share pathogenic mechanisms (i.e., inflammation starts around the ducts and both epithelial populations inappropriately express class II HLA molecules) despite the fact that a distinct autoantibody prolife is verified - patients with pSS usually present anti-Ro and anti-La antibodies, while in primary biliary cirrhosis the predominant specific autoantibodies are antimitochondrial antibodies [62]. Furthermore, the plasmatic detection of antimitochondrial antibodies in individuals affected by pSS, in the presence or absence of elevated liver enzymes, is highly indicative of early liver disease [55].

\section{Pulmonary involvement}

In SS-affected individuals, subclinical pulmonary inflammation exists in more than $30-50 \%$ of cases, and clinically significant pulmonary involvement can affect approximately $10 \%$ of patients and may be the first manifestation of the disease [64]. The predominant pattern of lung involvement is that of bronchial/bronchiolar disease, compared to interstitial lung disease. Other potential complications include lymphocytic alveolitis, lymphocytic interstitial pneumonitis and fibrosis, and pseudolymphoma. The main identified clinically symptom is cough generally a symptom of xerotrachea - while the most commonly identified findings in radiological exams are ground-glass attenuation, bronchiectasis, reticular pattern and honeycombing, involving predominantly the lower lobes [65].

\section{Neuropsychiatric involvement}

Neurologic disease is one of the most common manifestations of SS, affecting cranial and peripheral nerves, and more rarely the central nervous system (CNS). The eclectic permutation of peripheral nervous system (PNS) syndromes which occur in SS patients are among the most common and severe extraglandular complications [66]. Pure or predominantly sensory polyneuropathies are common neurologic manifestation (e.g. sensory ataxic or small fibre sensory painful neuropathy), while mononeuropathy multiplex, polyradiculopathy, symptomatic dysautonomia, cranial neuropathy and myopathy, are rarer complications.
Furthermore, SS patients can be affected by neuropathic pain, with small-fibre neuropathy causing lancinating or burning pain which can disproportionately affect the proximal torso, the extremities and the face [67].

CNS affection, which may occur with a bimodal temporal pattern, both at the onset of the disease and with a later development - is believed to be a rare but not negligible complication of SS. A variety of clinical manifestations has been recognized including diffuse, focal/multifocal, multiple sclerosis (MS)-like disease, isolated optic neuritis, transverse myelitis or psychiatric manifestations [68]. Interestingly, recent magnetic resonance imaging analysis showed that, comparing to controls, patients with pSS had decreased gray matter volume in the cortex, deep gray matter, and cerebellum. Associated loss of white matter volume was observed in areas corresponding to gray matter atrophy and in the corpus callosum [69].

Additionally, a relatively high rate of affective and cognitive symptoms, as well as abnormal fatigue has been reported in SS patients. They also exhibit a distinct pattern of personality traits and high levels of physiological distress [궁.

\section{Obstetrical and gynaecological involvement}

Dyspareunia secondary to impaired lubrication is verified in many premenopausal women with pSS [71]. Other gynaecological problems include vaginal dryness, endometriosis, episodes of amenorrhoea and menorrhagia/metrorrhagia $[\underline{71}, \underline{72}]$. In one study, positive information about surgery for endometriosis has been correlated with the presence of the antibodies anti-SSA and anti-SSB [73].

In pSS, pregnancy does not appear to influence disease course. Nonetheless there is a risk of neonatal lupus and congenital atrioventricular bloc associated with high morbidity and mortality, possibly related to maternal anti-SSA antibodies [74].

\section{Haematologic/oncologic involvement}

Anaemia of chronic disease and hypergammaglobulinemia are the most prevalent hematologic manifestations encountered at diagnosis and during the course of pSS [75]. Moreover, leucopenia, T-CD4 ${ }^{+}$ lymphocytopenia, agranulocytosis, thrombocytopenia, monoclonal gammopathies are also frequent findings, and broadly correlated with the presence of extraglandular symptoms, such as palpable purpura, lymphadenopathy, and splenomegaly $[75,76]$.

Patients with pSS show an increased risk of lymphoma development and, in fact, a clinically identified condition occurs in about $5-10 \%$ of SS-affected individuals. 
Lymphoprolipherative disorders, predominantly nonHodgkin's lymphoma of B-cell origin are the most frequent, being marginal zone B-cell lymphomas and diffuse large B-cell lymphomas the most predominant histological types [75].

\section{CONCLUSIONS}

The increasing number of data published recently on the aetiophatogenesis of Sjögren's syndrome strengthens the hypothesis that this condition, as all autoimmune diseases, is a multifactorial disorder. Genetic predisposition, hormonal and environmental factors are thought to be implicated. The absence of a local balance of pro-apoptotic and defensive repair signals seems to be the key aetiopathogenic mechanism leading to glandular damage. Consequently to glandular manifestations, the lymphocytic dysfunction seems to be more related to the extraglandular involvement of the disease. Additionally, the role of exogenous agents as triggering factors seems to be of relevance and needs to be further enlightened.

\section{ACKNOWLEDGMENTS AND DISCLOSURE STATEMENTS}

The authors declare that they have no conflict of interests.

\section{REFERENCES}

1. Fox R. Sjogren's syndrome. Lancet. 2005 Jul 23-29;366(9482):321-31. [Medline: 16039337] [doi: 10.1016/S0140-6736(05)66990-5]

2. Jonsson R, Bolstad A, Brokstad K, Brun J. Sjögren's syndrome-a plethora of clinical and immunological phenotypes with a complex genetic background. Ann N Y Acad Sci. 2007 Jun;1108:433-47. [Medline: 17894008] [doi: 10.1196/annals.1422.046]

3. Helmick C, Felson D, Lawrence R, Gabriel S, Hirsch R, Kwoh C, Liang M, Kremers H, Mayes M, Merkel P, Pillemer S, Reveille J, Stone J, Workgroup NAD. Estimates of the prevalence of athritis and other rheumatic conditions in the United States: part I. Arthritis Rheum. 2008 Jan;58(1):15-25. [Medline: 18163481] [doi: 10.1002/art.23177]

4. Vitali C, Bombardieri S, Jonsson R, Moutsopoulos H, Alexander E, Carsons S, Daniels T, Fox P, Fox R, Kassan S, Pillemer S, Talal N, Weisman M. Classification criteria for Sjögren's syndrome: a revised version of the European criteria proposed by the American-European Consensus Group. Ann Rheum Dis. 2002 Jun;61(6):554-8. [Medline: 12006334] [doi: 10.1136/ard.61.6.554] [FREE Full Text]

5. Ramos-Casals M, Tzioufas A, Font J. Primary Sjögren's syndrome: new clinical and therapeutic concepts. Ann Rheum Dis. 2005 Mar;64(3):347-54. Epub 2004 Oct 21. [Medline: 15498797] [doi: 10.1136/ard.2004.025676] [FREE Full Text]

6. Tzioufas A, Voulgarelis M. Update on Sjögren's syndrome autoimmune epithelitis: from classification to increased neoplasias. Best Pract Res Clin Rheumatol. 2007 Dec;21(6):989-1010. [Medline: 18068857] [doi: 10.1016/j.berh.2007.09.001]

7. Voulgarelis M, Skopouli F. Clinical, immunologic, and molecular factors predicting lymphoma development in Sjogren's syndrome patients. Clin Rev Allergy Immunol. 2007 Jun;32(3):265-74. [Medline: 17992593] [doi: $10.1007 / \mathrm{s} 12016-007-8001-\mathrm{x}$ ]

8. Reveille J. The molecular genetics of systemic lupus erythematosus and Sjögren's syndrome. Curr Opin Rheumatol. 1992 Oct;4(5):644-56. [Medline: 1419498]

9. Loiseau P, Lepage V, Djelal F, Busson M, Tamouza R, Raffoux C, Menkes C, Meyer O, Charron D, Goldberg D. HLA class I and class II are both associated with the genetic predisposition to primary Sjögren syndrome. Hum Immunol. 2001 Jul;62(7):725-31. [Medline: 11423179] [doi: 10.1016/S0198-8859(01)00253-1]

10. Manthorpe R, Morling N, Platz P, Ryder L, Svejgaard A, Thomsen M. HLA-D antigen frequencies in Sjögren's syndrome. Differences between the primary and secondary form. Scand J Rheumatol. 1981;10(2):124-8. [Medline: 6941466] [doi: 10.3109/03009748109095284]

11. Papasteriades C, Skopouli F, Drosos A, Andonopoulos A, Moutsopoulos H. HLA-alloantigen associations in Greek patients with Sjögren's syndrome. J Autoimmun. 1988 Feb;1(1):85-90. [Medline: 3151145] [doi: 10.1016/0896-8411(88)90079-0]

12. Bolstad A, Wassmuth R, Haga H, Jonsson R. HLA markers and clinical characteristics in Caucasians with primary Sjögren's syndrome. J Rheumatol. 2001 Jul;28(7):1554-62. [Medline: 11469461]

13. Cruz-Tapias P, Rojas-Villarraga A, Maier-Moore S, Anaya J-M. HLA and Sjögren's syndrome susceptibility. A metaanalysis of worldwide studies. Autoimmun Rev. 2012 Feb;11(4):281-7. Epub 2011 Oct 7. [Medline: 22001416] [doi: 10.1016/j.autrev.2011.10.002]

14. Nordmark G, Kristjansdottir G, Theander E, Eriksson P, Brun J, Wang C, Padyukov L, Truedsson L, Alm G, Eloranta M, Jonsson R, Rönnblom L, Syvänen A. Additive effects of the major risk alleles of IRF5 and STAT4 in primary Sjögren's syndrome. Genes Immun. 2009 Jan;10(1):68-76. Epub 2008 Dec 18. [Medline: 19092842] [doi: 10.1038/gene.2008.94] 
15. Mamtani M, Anaya J, He W, Ahuja S. Association of copy number variation in the FCGR3B gene with risk of autoimmune diseases. Genes Immun. 2010 Mar;11(2):155-60. Epub 2009 Sep 10. [Medline: 19741716] [doi: 10.1038/gene.2009.71]

16. Voulgarelis M, Tzioufas A. Pathogenetic mechanisms in the initiation and perpetuation of Sjögren's syndrome. Nat Rev Rheumatol. 2010 Sep;6(9):529-37. Epub 2010 Aug 3. [Medline: 20683439] [doi: 10.1038/nrrheum.2010.118]

17. Lee T, Chiang B. Sex differences in spontaneous versus induced animal models of autoimmunity. Autoimmun Rev. 2012 May;11(6-7):A422-9. Epub 2011 Dec 4. [Medline: 22172712] [doi: 10.1016/j.autrev.2011.11.020]

18. Forsblad-d'Elia H, Carlsten H, Labrie F, Konttinen Y, Ohlsson C. Low serum levels of sex steroids are associated with disease characteristics in primary Sjogren's syndrome; supplementation with dehydroepiandrosterone restores the concentrations. J Clin Endocrinol Metab. 2009 Jun;94(6):2044-51. Epub 2009 Mar 24. [Medline: 19318446] [doi: 10.1210/jc.2009-0106]

19. Porola P, Laine M, Virkki L, Poduval P, Konttinen Y. The influence of sex steroids on Sjögren's syndrome. Ann N Y Acad Sci. 2007 Jun;1108:426-32. [Medline: 17894007] [doi: 10.1196/annals.1422.045]

20. Valtysdóttir S, Wide L, Hällgren R. Low serum dehydroepiandrosterone sulfate in women with primary Sjögren's syndrome as an isolated sign of impaired HPA axis function. J Rheumatol. 2001 Jun;28(6):1259-65. [Medline: 11409117$]$

21. Banchereau J, Pascual V. Type I interferon in systemic lupus erythematosus and other autoimmune diseases. Immunity. 2006 Sep;25(3):383-92. [Medline: 16979570] [doi: 10.1016/j.immuni.2006.08.010]

22. Båve U, Nordmark G, Lövgren T, Rönnelid J, Cajander S, Eloranta M, Alm G, Rönnblom L. Activation of the type I interferon system in primary Sjögren's syndrome: a possible etiopathogenic mechanism. Arthritis Rheum. 2005 Apr;52(4):1185-95.Medline: 15818675] [doi: 10.1002/art.20998]

23. Fox R, Chilton T, Scott S, Benton L, Howell F, Vaughan J. Potential role of Epstein-Barr virus in Sjögren's syndrome. Rheum Dis Clin North Am. 1987 Aug;13(2):275-92.. [Medline: 2827246]

24. Burns J. Persistent cytomegalovirus infection--the aetiology of Sjogren's syndrome. Med Hypotheses. 1983 Apr;10(4):451-60. [Medline: 6308404] [doi: 10.1016/0306-9877(83)90011-7]

25. Moutsopoulos H, Manoussakis M. Immunopathogenesis of Sjogren's syndrome: "facts and fancy". Autoimmunity. 1989;5(1-2):17-24. [Medline: 2519015]

26. Hansen A, Lipsky P, Dörner T. Immunopathogenesis of primary Sjögren's syndrome: implications for disease management and therapy. Curr Opin Rheumatol. 2005 Sep;17(5):558-65. [Medline: 16093833] [doi: 01.bor.0000172801.56744.c3]

27. Ercolini A, Miller S. The role of infections in autoimmune disease. Clin Exp Immunol. 2009 Jan;155(1):1-15. [Medline: 19076824 ] [doi: 10.1111/j.1365-2249.2008.03834.x]

28. Ramos-Casals M, De Vita S, Tzioufas A. Hepatitis C virus, Sjögren’s syndrome and B-cell lymphoma: linking infection, autoimmunity and cancer. Autoimmun Rev. 2005 Jan;4(1):8-15. [Medline: 15652773] [doi: 10.1016/j.autrev.2004.04.004]

29. García-Carrasco M, Ramos M, Cervera R, Font J, Vidal J, Muñoz F, Miret C, Espinosa G, Ingelmo M. Hepatitis C virus infection in 'primary' Sjögren's syndrome: prevalence and clinical significance in a series of 90 patients. Ann Rheum Dis. 1997 Mar;56(3):173-5.. [Medline: 9135219] [doi: 10.1136/ard.56.3.173] [FREE Full Text]

30. Esteban J, Esteban R, Viladomiu L, López-Talavera J, González A, Hernández J, Roget M, Vargas V, Genescà J, Buti M. Hepatitis C virus antibodies among risk groups in Spain. Lancet. 1989 Aug 5;2(8658):294-7. [Medline: 2569102] [doi: 10.1016/S0140-6736(89)90485-6]

31. Busamia B, Gonzalez-Moles M, Ruiz-Avila I, Brunotto M, Gil-Montoya J, Bravo M, Gobbi C, Finkelberg A. Cell apoptosis and proliferation in salivary glands of Sjögren's syndrome. J Oral Pathol Med. 2011 Apr 26. doi: 10.1111/j.16000714.2011.01042.x. [Epub ahead of print] [Medline: 21521368] [doi: 10.1111/j.1600-0714.2011.01042.x]

32. Nguyen C, Peck A. Unraveling the pathophysiology of Sjogren syndrome-associated dry eye disease. Ocul Surf. 2009 Jan;7(1):11-27. [Medline: 19214349] [doi 10.1016/S1542-0124(12)70289-6]

33. Ulbricht K, Schmidt R, Witte T. Antibodies against alpha-fodrin in Sjögren's syndrome. Semin Arthritis Rheum. 2003 Aug;33(1):49-65. [Medline: 12848967] [doi: 10.1016/S1568-9972(03)00002-8]

34. Manganelli P, Fietta P. Apoptosis and Sjögren syndrome. Semin Arthritis Rheum. 2003;33:49-65. [Medline: 12920696] [doi: 10.1053/sarh.2003.50019]

35. Kong L, Ogawa N, McGuff H, Nakabayashi T, Sakata K, Masago R, Vela-Roch N, Talal N, Dang H. Bcl-2 family expression in salivary glands from patients with primary Sjögren's syndrome: involvement of Bax in salivary gland destruction. Clin Immunol Immunopathol. 1998 Aug;88(2):133-41. [Medline: 9714690] [doi: 10.1006/clin.1998.4556]

36. Azuma M, Motegi K, Aota K, Hayashi Y, Sato M. Role of cytokines in the destruction of acinar structure in Sjögren's syndrome salivary glands. Lab Invest. 1997 Sep;77(3):269-80. [Medline: 9314950]

37. Hanemaaijer R, Visser H, Konttinen Y, Koolwijk P, Verheijen J. Anovel and simple immunocapture assay for determination of gelatinase-B (MMP-9) activities in biological fluids: saliva from patients with Sjögren's syndrome contain increased latent and active gelatinase-B concentrations. Matrix Biol. 1998 Dec;17(8-9):657-65. [Medline: 9923658] [doi: 10.1016/S0945-053X(98)90116-0]

38. Higashi K, Yoshida M, Igarashi A, Ito K, Wada Y, Murakami S, Kobayashi D, Nakano M, Sohda M, Nakajima T, Narita I, Toida T, Kashiwagi K, Igarashi K. Intense correlation between protein-conjugated acrolein and primary Sjögren's syndrome. Clin Chim Acta. 2010 Mar;411(5-6):359-63. Epub 2009 Dec 5. [Medline: 19968980] [doi: 10.1016/i.cca.2009.11.032] 
39. Pérez P, Kwon Y, Alliende C, Leyton L, Aguilera S, Molina C, Labra C, Julio M, Leyton C, González M. Increased acinar damage of salivary glands of patients with Sjögren's syndrome is paralleled by simultaneous imbalance of matrix metalloproteinase 3/tissue inhibitor of metalloproteinases 1 and matrix metalloproteinase 9/tissue inhibitor of metalloproteinases 1 ratios. Arthritis Rheum. 2005 Sep;52(9):2751-60. [Medline: 16142742] [doi: 10.1002/art.21265]

40. Goicovich E, Molina C, Pérez P, Aguilera S, Fernández J, Olea N, Alliende C, Leyton C, Romo R, Leyton L, González M-J. Enhanced degradation of proteins of the basal lamina and stroma by matrix metalloproteinases from the salivary glands of Sjögren's syndrome patients: Correlation with reduced structural integrity of acini and ducts. Arthritis Rheum. 2003 Sep;48(9):2573-84. [Medline: 13130477] [doi: 10.1002/art.11178]

41. Boutsi E, Paikos S, Dafni U, Moutsopoulos H, Skopouli F. Dental and periodontal status of Sjögren's syndrome. J Clin Periodontol. 2000 Apr;27(4):231-5. [Medline: 10783835] [doi: 10.1034/j.1600-051x.2000.027004231.x]

42. Kuru B, McCullough M, Yilmaz S, Porter S. Clinical and microbiological studies of periodontal disease in Sjögren syndrome patients. J Clin Periodontol. 2002 Feb;29(2):92-102. [Medline: 11908470] [doi: 10.1034/j.1600-051x.2002.290202.x]

43. Almståhl A, Wikström M, Kroneld U. Microflora in oral ecosystems in primary Sjögren's syndrome. J Rheumatol. 2001 May;28(5):1007-13. [Medline: 11361180$]$

44. Kassan S, Moutsopoulos H. Clinical manifestations and early diagnosis of Sjogren syndrome. Arch Intern Med. 2004 Jun 28;164(12):1275-84. [Medline: 15226160] [doi: 10.1001/archinte.164.12.1275]

45. Lemp M. Evaluation and differential diagnosis of keratoconjunctivitis sicca. J Rheumatol Suppl. 2000;61:11-4. [Medline: 11128698$]$

46. Friedlaender M. Ocular manifestations of Sjögren's syndrome: keratoconjunctivitis sicca. Rheum Dis Clin North Am. 1992 Aug;18(3):591-608. [Medline: 1496163]

47. Vitali C, Tavoni A, Neri R, Castrogiovanni P, Pasero G, Bombardieri S. Fibromyalgia features in patients with primary Sjögren's syndrome. Evidence of a relationship with psychological depression. Scand J Rheumatol. 1989;18(1):21-7. [Medline: 2704982] [ doi: 10.3109/03009748909095399]

48. Al-Hashimi I, Khuder S, Haghighat N, Zipp M. Frequency and predictive value of the clinical manifestations in Sjögren's syndrome. J Oral Pathol Med. 2001 Jan;30(1):1-6. [Medline: 11140894] [doi: 10.1034/j.1600-0714.2001.300101.x]

49. Tobón G, Roguedas A-M, Misery L, Youinou P, Pers J-O. Skin biopsy as a routine diagnostic tool for primary Sjögren's syndrome. Int J Clin Rheumatol. 2011;6:291-6. [doi: 10.2217/ijr.11.19]

50. García-Carrasco M, Sisó A, Ramos-Casals M, Rosas J, de la Red G, Gil V, Lasterra S, Cervera R, Font J, Ingelmo M. Raynaud's phenomenon in primary Sjögren's syndrome. Prevalence and clinical characteristics in a series of 320 patients. J Rheumatol. 2002 Apr;29(4):726-30. [Medline: 11950013]

51. Kraus A, Caballero-Uribe C, Jakez J, Villa A, Alarcón-Segovia D. Raynaud's phenomenon in primary Sjögren's syndrome. Association with other extraglandular manifestations. Rheumatol. 1992 Oct;19(10):1572-4. [Medline: 1464870]

52. Ramos-Casals M, Anaya J, García-Carrasco M, Rosas J, Bové A, Claver G, Diaz L, Herrero C, Font J. Cutaneous vasculitis in primary Sjögren syndrome: classification and clinical significance of 52 patients. Medicine (Baltimore). 2004 Mar;83(2):96-106. [Medline: 15028963] [doi: 10.1097/01.md.0000119465.24818.98]

53. Scofield R. Vasculitis in Sjögren's Syndrome. Curr Rheumatol Rep. 2011 Dec;13(6):482-8. doi: 10.1007/s11926-0110207-5. [Medline: 21870104] [doi: 10.1007/s11926-011-0207-5]

54. Volter F, Fain O, Mathieu E, Thomas M. Esophageal function and Sjögren's syndrome. Dig Dis Sci. 2004 Feb;49(2):24853. [Medline: 15104365] [doi: 10.1023/B:DDAS.0000017446.64582.62]

55. Ebert E. Gastrointestinal and Hepatic Manifestations of Sjogren Syndrome. J Clin Gastroenterol. 2012 Jan;46(1):25-30. [Medline: 22157220] [doi: 10.1097/MCG.0b013e3182329d9c]

56. Belafsky P, Postma G. The laryngeal and esophageal manifestations of Sjögren's syndrome. Curr Rheumatol Rep. 2003 Aug;5(4):297-303. [Medline: 14531957] [doi: 10.1007/s11926-003-0008-6]

57. Bossini N, Savoldi S, Franceschini F, Mombelloni S, Baronio M, Cavazzana I, Viola B, Valzorio B, Mazzucchelli C, Cattaneo R, Scolari F, Maiorca R. Clinical and morphological features of kidney involvement in primary Sjögren's syndrome. Nephrol Dial Transplant. 2001 Dec;16(12):2328-36. [Medline: 11733624] [doi: 10.1093/ndt/16.12.2328]

58. Bossini N, Savoldi S, Franceschini F, Mombelloni S, Baronio M, Cavazzana I, Viola B, Valzorio B, Mazzucchelli C, Cattaneo R, Scolari F, Maiorca R. Clinical and morphological features of kidney involvement in primary Sjogren's syndrome. Nephrol Dial Transplant. 2001 Dec;16(12):2328-36 [Medline: 11733624] [doi: 10.1093/ndt/16.12.2328]

59. Pertovaara M, Korpela M, Kouri T, Pasternack A. The occurrence of renal involvement in primary Sjögren's syndrome: a study of 78 patients. Rheumatology (Oxford). 1999 Nov;38(11):1113-20. [Medline: 10556265] [doi: 10.1093/rheumatology/38.11.1113]

60. Moutsopoulos H, Cledes J, Skopouli F, Elisaf M, Youinou P. Nephrocalcinosis in Sjogren's syndrome: a late sequela of renal tubular acidosis. J Intern Med. 1991 Aug;230(2):187-91. [Medline: 1865172] [doi: $10.1111 / \mathrm{j} .1365-2796.1991 . t b 00429 . x$ ]

61. Goules A, Masouridi S, Tzioufas A, Ioannidis J, Skopouli F, Moutsopoulos H. Clinically significant and biopsydocumented renal involvement in primary Sjögren syndrome. Medicine (Baltimore). 2000 Jul;79(4):241-9. [Medline: 10941353] [doi: 10.1097/00005792-200007000-00005] 
62. Abraham S, Begum S, Isenberg D. Hepatic manifestations of autoimmune rheumatic diseases. Ann Rheum Dis. 2004 Feb;63(2):123-9. [Medline: 14722198] [doi: 10.1136/ard.2002.001826]

63. Golding P, Bown A, Mason A, Taylor E. Sicca complex in liver disease. Br Med J. 1970 Nov 7;4(5731):340-2. [Medline: 5472806] [doi: 10.1136/bmj.4.5731.340]

64. Hatron P-Y, Tillie-Leblond I, Launay D, Hachulla E, Fauchais A, Wallaert B. Pulmonary manifestations of Sjögren's syndrome. Presse Med. 2011 Jan;40(1 Pt 2):e49-64. Epub 2010 Dec 30. [Medline:21194883] [doi: 10.1378/chest.70.3.354]

65. Yazisiz V, Arslan G, Ozbudak I, Turker S, Erbasan F, Avci A, Ozbudak O, Terzioglu E. Lung involvement in patients with primary Sjögren's syndrome: what are the predictors? Rheumatol Int. 2010 Aug;30(10):1317-24. Epub 2009 Oct 21. [Medline: 19844720 ] [doi: $10.1007 / \mathrm{s} 00296-009-1152-8$ ]

66. Sène D, Jallouli M, Lefaucheur J, Saadoun D, Costedoat-Chalumeau N, Maisonobe T, Diemert M, Musset L, Haroche J, Piette J, Amoura Z, Cacoub P. Peripheral neuropathies associated with primary Sjögren syndrome: immunologic profiles of nonataxic sensory neuropathy and sensorimotor neuropathy. Medicine (Baltimore). 2011 Mar;90(2):133-8. [Medline: 21358442] [doi: 10.1097/MD.0b013e31820fd2d1]

67. Birnbaum J. Peripheral nervous system manifestations of Sjögren syndrome: clinical patterns, diagnostic paradigms, aetiopathogenesis, and therapeutic strategies. Neurologist. 2010 Sep;16(5):287-97. [Medline: 20827117] [doi: 10.1097/NRL.0b013e3181ebe59f]

68. Massara A, Bonazza S, Castellino G, Caniatti L, Trotta F, Borrelli M, Feggi L, Govoni M. Central nervous system involvement in Sjögren's syndrome: unusual, but not unremarkable--clinical, serological characteristics and outcomes in a large cohort of Italian patients. Rheumatology (Oxford). 2010 Aug;49(8):1540-9. Epub 2010 May 5. [Medline: 20444860] [doi: 10.1093/rheumatology/keq111]

69. Tzarouchi L, Tsifetaki N, Konitsiotis S, Zikou A, Astrakas L, Drosos A, Argyropoulou M. CNS involvement in primary Sjogren Syndrome: assessment of gray and white matter changes with MRI and voxel-based morphometry. AJR Am J Roentgenol. 2011 Nov;197(5):1207-12.. [Medline: 22021516] [doi: 10.2214/AJR.10.5984]

70. Segal B, Carpenter A, Walk D. Involvement of nervous system pathways in primary Sjögren's syndrome. Rheum Dis Clin North Am. 2008 Nov;34(4):885-906, viii. [Medline: 18984410] [doi: 10.1016/j.rdc.2008.08.001]

71. Marchesoni D, Mozzanega B, De Sandre P, Romagnolo C, Gambari P, Maggino T. Gynaecological aspects of primary Sjogren's syndrome. Eur J Obstet Gynecol Reprod Biol. 1995 Nov;63(1):49-53. [Medline: 8674565] [doi: 10.1016/0301-2115(95)02224-U]

72. Lehrer S, Bogursky E, Yemini M, Kase NG, Birkenfeld A. Gynecologic manifestations of Sjögren's syndrome. Am J Obstet Gynecol. 1994 Mar;170(3):835-7. [Medline: 8141212]

73. Haga HJ, Gjesdal CG, Irgens LM, Ostensen M. Reproduction and gynaecological manifestations in women with primary Sjögren's syndrome: a case-control study. Scand J Rheumatol. 2005;34(1):45-8. [Medline: 15903025] [doi: 10.1080/03009740510017959]

74. Picone O, Alby C, Frydman R, Mariette X. [Sjögren syndrome in Obstetric and Gynecology: literature review]. J Gynecol Obstet Biol Reprod (Paris). 2006 Apr;35(2):169-75. Review. French. [Medline: 16575363] [doi: $10.1016 / \mathrm{S} 0368-2315(06) 76391-8$ ]

75. Baimpa E, Dahabreh IJ, Voulgarelis M, Moutsopoulos HM. Hematologic manifestations and predictors of lymphoma development in primary Sjögren syndrome: clinical and pathophysiologic aspects. Medicine (Baltimore). 2009 Sep;88(5):284-93.. [Medline: 19745687] [doi: 10.1097/MD.0b013e3181b76ab5]

76. Ramos-Casals M, Font J, Garcia-Carrasco M, Brito MP, Rosas J, Calvo-Alen J, Pallares L, Cervera R, Ingelmo M. Primary Sjögren syndrome: hematologic patterns of disease expression. Medicine (Baltimore). 2002 Jul;81(4):281-92. Review. [Medline: 12169883] [doi: 10.1097/00005792-200207000-00004]

\section{To cite this article:}

Gomes PD, Juodzbalys G, Fernandes MH, Guobis Z. Advances in the Aetiophatogenesis of Sjögren's Syndrome: a Literature Review.

J Oral Maxillofac Res 2012;3(1):e2

URL: http://www.ejomr.org/JOMR/archives/2012/1/e2/v3n1e2ht.pdf

doi: $10.5037 /$ jomr.2012.3102 
Copyright (C) Gomes PD, Juodzbalys G, Fernandes MH, Guobis Z. Accepted for publication in the JOURNAL OF ORAL \& MAXILLOFACIAL RESEARCH (http://www.ejomr.org), 17 March 2012

This is an open-access article, first published in the JOURNAL OF ORAL \& MAXILLOFACIAL RESEARCH, distributed under the terms of the Creative Commons Attribution-Noncommercial-No Derivative Works 3.0 Unported License, which permits unrestricted non-commercial use, distribution, and reproduction in any medium, provided the original work and is properly cited. The copyright, license information and link to the original publication on (http://www.ejomr.org) must be included. 